\title{
Why I love Twitter
}

\author{
Carol Randall, \\ University of Greenwich, School of Education
}

I have always been interested in the idea of social networking as a means of keeping up to date with my profession. I began by joining mailing lists, then made a brief foray into Facebook, Linkedln and Pinterest, but didn't really become comfortable with using any of them professionally. Facebook is, for me, a way of keeping up to date with what my extended family are doing. I do not have any non-family "Facebook friends", and I protect my privacy fiercely. Pinterest is a good way of collecting information together, and I have recently begun to use it again as a "virtual scrapbook" - but have not as yet engaged in communication with other Pinterest users. I do have a Linkedln account, but have not yet worked out how to use it, so cannot really gauge how useful Linkedln might be.

I tried blogging for a while (and still do this sporadically), but it was only when I discovered Twitter that I really started to develop an online personal learning network. One of the reasons I prefer Twitter is the limit of 140 characters per post, which means I don't have to think about conventions for writing, but can express ideas and ask questions quickly. 'By encouraging shorter posts, it lowers users' requirement of time and thought investment for content generation". (Java et al., 2007).

Like many people, I chose a Twitter name, or "handle" (@caro_lann) and started by following a few friends. Then I found a few maths and science "celebrities", then a few authors, and gradually built up to the 300 or so people I follow now.

I found some educators on Twitter, and realised that I could learn from them. I found a Twitter chat (\#ukedchat), and found more educators by following that hashtag for a while. One hashtag led to another, and soon I was contributing to \#ukedchat, \#edchat (the international version) and \#mathchat, where I found mathematicians, maths teachers and maths teacher-educators.

I use Twitter to keep up to date with policy related to my profession - I follow the Twitter feed from government departments (BIS and the DfE); and also follow some newsreaders, who give a personal slant on news and politics. I still get a little kick from receiving personal replies from Jon Snow or Riz Lateef when I have tweeted them a question.

I have just checked my "followers" list, and realise that as of today, I have 462 followers - that is 462 people who have chosen to see my tweets in their timeline. I have not made a conscious effort to build up a following - I don't tweet very regularly - not even every day, but knowing that these people are reading what I say makes me select what I tweet quite carefully. I occasionally make a reference to the weather, or comment on a news item or TV programme, but most often I post links to interesting things I have seen elsewhere on the Internet, which relate to teaching in one way or another.

Some people curate lists of like-minded "tweeps"; and I am now listed by twenty different people, under various headings - maths, science, $\mathrm{HE}$, FE, education etc. Lists are useful. If I want to ask a question related to further education policy for example, I can send a tweet directly to the people on my "FE policy" list, maximising the chance of getting a reply. 
There are disadvantages to Twitter: it can, if allowed, become a "time-sponge"; the strict character limit for a tweet sometimes means that an idea will be underdeveloped, and links to content can be affected when tweets are re-tweeted if this is not done carefully. A Twitter timeline is ephemeral - tweets can easily become lost among a stream of updates from hundreds of people, and important or useful ideas need to be saved in some way - I usually e-mail tweets to myself if I want to refer to them again.

If you would like to see what my Twitter account looks like without signing up, you can find me at Twitter. com/Caro_lann , or if you already tweet, my "handle" is @caro_lann.

I really feel that I am part of a community. I have met some of the people I follow (and who follow me) face-to-face, but most I only know from Twitter. We share ideas and resources, links to interesting articles and blog posts, and occasionally, (but not too often), share glimpses of our lives outside of education.

Mollett, A. et al., (2011) have produced a useful guide for academics who wish to start using Twitter, which provides much more information than I can in this short reflection on my own practice

Twitter is not only about sharing what we have for breakfast. It can be a very useful professional network. Give it a try.

\section{References}

Java, A. et al., (2007) Why We Twitter: Understanding Microblogging Usage and Communities Proceedings of the Joint 9th WEBKDD and 1st SNA-KDD Workshop 2007 University of Maryland.[Online]. Available at http://ebiquity.umbc.edu/paper/html/id/367/Why-We-TwitterUnderstanding-Microblogging-Usage-and- Communities [Accessed August 2012].

Mollett, A. et al., (2011) Using Twitter in University Research, Teaching and Impact Activities LSE Public Policy Group. [Online]. Available at: http://blogs.Ise.ac.uk/impactofsocialsciences/2011/09/29/Twitter_ guide/ [Accessed August 2012].

\section{Author Biography}

Carol Randall is a senior lecturer in lifelong learning teacher education in the School of Education at the University of Greenwich. She started her career teaching mathematics to engineering students in a further education college before moving into in-house professional development and later joining the university as a teacher educator.

A "hashtag" is a search term, e.g. \#Greenwich would find all recent tweets which also had \#Greenwich in them. 